\title{
Interrupted pulse electromagnetic expanding ring test for sheet metal
}

\author{
José Imbert ${ }^{\mathrm{a}}$, Taamjeed Rahmaan, and Michael Worswick \\ Department of Mechanical and Mechatronics Engineering, University of Waterloo, Waterloo, Ontario, Canada, N2L 3G1
}

\begin{abstract}
This paper describes the development of an interrupted pulse electromagnetic (EM) expanding ring experiment to study the high rate properties of AA5182 aluminum commercial sheet alloys at strain rates in excess of 5,000 $\mathrm{s}^{-1}$. Experiments are performed to compare two commonly adopted methods of driving the expanding ring: EM expansion versus an exploding wire. After studying and testing both methods, it was determined that EM expansion had the greatest potential for being developed into a test that would result in free-flight of the samples. By interrupting the current pulse in the EM expanding ring test, the ring is allowed to achieve free-flight, thus eliminating the need to determine the induced EM forces and significantly reducing the uncertainty of the stress-strain behaviour determined from the test. Once the free-flight condition is established, the stress-strain behaviour of the material is determined from the free-flight deceleration of the sample, as calculated from the velocity measured using a Photon Doppler Velocimeter (PDV). Results are presented for AA5182 at strains rates between 1,000 to 5,500 s exhibit low strain rate sensitivity, are comparable to tensile split-Hopkinson bar results at strain rates of $1,000 \mathrm{~s}^{-1}$.
\end{abstract}

\section{Introduction}

The current push for automotive vehicle light weighting has resulted in considerable interest in the application of aluminum alloys and advanced high strength steels in automotive mass production. Unfortunately, these material exhibit only moderate formability when compared to traditional low carbon steel alloys. The formability of some of these alloys has been shown to increase with the use of high speed forming techniques [1-4] such as electromagnetic (EM) and electrohydraulic forming. When these high speed techniques are used to form material into a die, strain rates in excess of $10,000 \mathrm{~s}^{-1}$ are predicted to occur during the interaction of the tool with the sheet $[3,4]$. The mechanisms that result in the observed increases in formability are not yet fully understood, in part due to the lack of understanding of the properties of sheet metals at such high rates of strain, which significantly limits the ability to model these processes. A practical test that can generate stress-strain data at these high rates is required to better understand high speed forming techniques and produce accurate material models. The expanding ring technique is one of a few with potential to satisfy this need and it is the subject of this work.

The expanding ring test generates uniaxial tensile stresses and high strain rates within a sample ring, by causing it to expand radially at high speeds (Fig. 1). If the ring is in free-flight or under the effect of a known driving force, the stress-strain behaviour of the material can be extracted by measuring its radial deceleration. Accurately determining the driving force can be very difficult in practice; thus, a test where no driving force is present, where the ring is allowed to decelerate in free-flight would present an ideal condition.

\footnotetext{
${ }^{a}$ Corresponding author: jmsimber@uwaterloo.ca
}

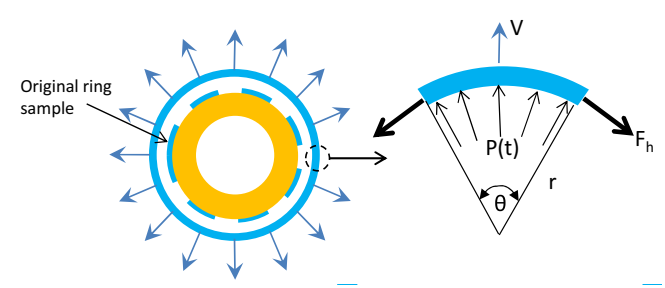

Figure 1. Schematic of an expanding ring test. $\mathrm{V}=$ radial velocity, $\mathrm{F}_{h}=$ internal force, $\mathrm{P}(\mathrm{t})=$ driving pressure.

In principle, obtaining the stress strain behaviour for a material from an expanding ring test is relatively easy, assuming the ring is in a uniaxial stress state and only deforming radially (Fig. 1). The governing equation is [5]:

$$
F=m a .
$$

Where is $F=$ force, $m=$ mass and $a=$ acceleration. Applying equilibrium to a segment of the ring, as illustrated in Fig. 1;

$$
-2 F_{h} \operatorname{Sin}\left(\frac{\theta}{2}\right)+F_{P(t)}=m \frac{d V}{d T}
$$

Where $F_{h}=$ internal force, $F_{P}(t)=$ driving force generated by a driving pressure $\mathrm{P}(\mathrm{t})$ and $v=$ velocity. The simplest and most accurate analysis is obtained when $F_{P}(t)=0$, corresponding to free-flight, which results in;

$$
-2 F_{h} \operatorname{Sin}\left(\frac{\theta}{2}\right)=m \frac{d V}{d T} .
$$

After some basic manipulation we can obtain the stress, $\sigma$, in terms of the density, $\rho$, the radius, $r$, and the radial acceleration, $\ddot{r}$;

$$
\sigma=\rho r \ddot{r}
$$

This is an Open Access article distributed under the terms of the Creative Commons Attribution License 4.0, which permits unrestricted use, distribution, and reproduction in any medium, provided the original work is properly cited. 
The strain and strain rate are respectively given by [5];

$$
\begin{gathered}
\varepsilon=\frac{\Delta r}{r} \\
\dot{\varepsilon}=\frac{\varepsilon}{\Delta t}=\frac{\dot{r}}{r} .
\end{gathered}
$$

Obtaining the radial acceleration is crucial for the accurate determination of the stress. It is also difficult to measure during a ring expansion test, in which radial velocities can exceed $100 \mathrm{~m} / \mathrm{s}$ and test durations are in the order of $50 \mu \mathrm{s}$. Early implementations of the tests used high speed photography or streak cameras to measure the displacement and determined the acceleration by differentiating the velocity twice. Determining acceleration from displacement is inherently noisy, which led to the adaptation of laser interferometry techniques to measure velocity directly $[6,7]$.

Early ring expansion tests accelerated the ring by placing it on the outside of a hardened steel cylinder and using an explosive to create a stress wave in the cylinder that would expand the ring [5,8]. This method led to significant free-flight of the sample. Unfortunately, the health and safety constraints that result from using high explosives make this method impractical for most applications. Currently, the two preferred ways of performing the test are the EM expansion and the exploding wire tests. In EM expansion the ring is accelerated using the induced forces generated by current pulse flowing through a nearby spiral coil. This technique was introduced by $[9,10]$. EM expansion is effective for high conductivity, relatively low strength materials, such as copper and aluminium, but it is not as effective for lower conductivity, high strength materials, such as steels. High conductivity drivers can be used to test low conductivity materials [9], but they reduce the efficiency of the apparatus and introduce additional complications to the apparatus and analysis. In addition, spiral coils do not produce a uniformly distributed induced force, which will result in violations of the analysis assumptions. Recent implementation of EM expanding ring tests have begun to use Photon Doppler Velocimeters (PDV) to measure the velocity [12-17].

In the exploding wire test, a wire is placed within an elastomer and vaporized using a high frequency high current pulse $[17,18]$. The energy of the expanding gases is transmitted to the ring through the elastomer, which is referred to as a driver or actuator. Since the test does not rely on induced forces, it eliminates the effects of conductivity. However, the driving force produced by the driver is difficult to determine, as is the exact interaction between the driver and the specimen.

To account for the difficulties in determining the driving forces, both the EM and exploding wire expanding ring tests have been combined with finite element and optimization methods to achieve better constitutive data fits [17,19]. These methods have potential; however, significant errors can be introduced in the analysis.

To the authors' knowledge, there has been no significant effort to develop and fully understand the testing of sheet metal using the expanding ring technique.

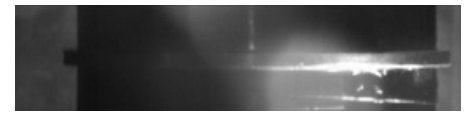

(a) $\mathrm{t}=0.000026667 \mathrm{sec}$

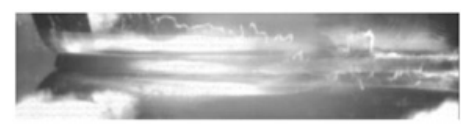

(b) $\mathrm{t}=0.000090000 \mathrm{sec}$

Figure 2. High speed images taken at $300,000 \mathrm{fps}$ of an expanding ring test: a) as expansion begins and b) after the ring has expanded. Note how the polyurethane engulfs the ring in b).

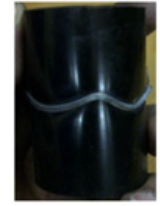

(a)

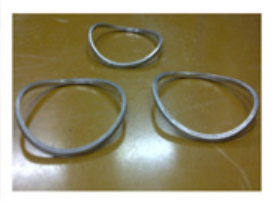

(b)
Figure 3. Out-of-plane ring deformation believed to be the result of material anisotropy and frictional forces.

Sheet metal poses challenges to the expanding ring technique, due to the anisotropy of the material and the difficulty of obtaining specimens that accurately represent the properties of the sheet metal. This work is part of an effort to develop such a test for AA 5182 and DP 600 sheet metal. Both the EM and exploding wire techniques were explored. The limitations of the EM expanding ring, as described above, were evident in the present work and exacerbated, since the AA 5182 and DP 600 are structural alloys with a significantly higher strength than the pure aluminum or copper used in many reported expanding ring experiments and in the case of the DP 600, have lower conductivity. The two main limitations of the EM expanding ring test for this work were the very low coil life and the presence of a driving force thought the expansion of the ring.

The evaluation of the exploding wire technique also revealed significant challenges. High speed video of the tests showed that the rings were in contact with the driver for the recorded expansion. In some cases the expanding driver can engulf the ring, as shown in Fig. 2, for a DP600 ring of $1 \mathrm{~mm} \times 1 \mathrm{~mm}$ cross section, tested at $4.3 \mathrm{~kJ}$, using $80 \mathrm{~A}$ polyurethane. The tests also results in significant friction between the specimen and the driver that result in non-uniaxial stress states on the rings. These stress states can contribute to significant non-radial, out-of-plane deformation of the specimens, as can be seen in Fig. 3. A combination of a polyamide film and lubricant was used to reduce the friction; however, it was not eliminated. The result of the lubrication can be seen by comparing the results of a non-lubricated test (Fig. 3-a) to a test where the lubrication was used (Fig. 3-b).

After studying and testing both methods, it was determined that an interrupted current EM ring expansion test had the greatest potential for being developed into a test that would result in free-flight of the samples. By interrupting the current pulse in the EM expanding ring test, the ring is allowed to achieve free-flight, thus eliminating the need to determine the induced forces, 


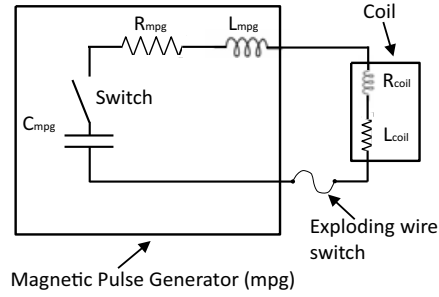

Figure 4. Schematic of the experimental apparatus.

significantly reducing the uncertainty of the stress-strain behaviour determined from the test. The following sections will describe the interrupted pulse test developed and present the results from tests on AA 5182, which yielded strain rates between 1,000 to $5,500 \mathrm{~s}^{-1}$.

\section{Experimental methods and procedures}

\subsection{Experimental apparatus}

A schematic view of the expanding ring apparatus is shown in Fig. 4. It consists of a magnetic pulse generator (MPG), essentially a large capacitor bank, and a coil. When the charged capacitors are discharged through a coil, a current pulse is generated, which induces the driving forces on the sample ring. A typical EM expanding ring apparatus will have a similar schematic, but without the exploding wire switch used in the present work. For a more in depth overview on the basic principles the reader is referred to $[1,20]$.

\subsubsection{Magnetic pulse generator}

The magnetic pulse generator used for this work was a Pulsar MPW 20 Research Edition Magnetic Pulse Generator (MPG). The MPG consists of a capacitor bank and a power supply to deliver the current to the capacitors at the required specifications. The MPG has a nominal maximum energy capacity of $20 \mathrm{~kJ}$ and a maximum charging voltage of 9,000 volts. The machine capacitance is $539.7 \mu \mathrm{F}$, inductance is $24.35 \mathrm{nH}$, and resistance is $2.98 \mathrm{~m} \Omega$. The nominal discharge frequency using a shorting bar across the output terminals of the capacitor bank was $24.51 \mathrm{kHz}$. For the present work the MPG was charged to $4.0 \mathrm{kV}$, which results in a stored energy of $4.3 \mathrm{~kJ}$.

\subsubsection{Pulse interruption}

The current pulses used for an EM expanding ring test have peaks of in the order of $100 \mathrm{kA}$ and frequencies above $10 \mathrm{kHz}$ which makes interrupting the pulse very difficult since mechanical switches that can function at these speeds are not available. In principle, solid state devices could be used, but the authors were not able to find a source for one that could be used for this work. Another alternative is to use an explosive event to produce the switch. Gourdin [10] used a shaped explosive charge switch to interrupt the current by creating an alternate current path, with the intent of reducing the temperature rise on the samples caused by

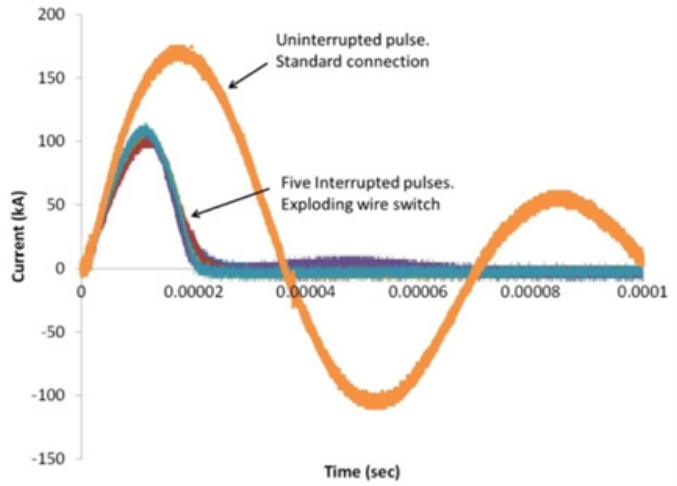

Figure 5. Comparison of uninterrupted and five interrupted current pulses.

Joule heating. Switches based on exploding aluminum foil were developed by [21] to interrupt and shape pulses.

For this work exploding wires were used to open the circuit and interrupt the current pulse. When the current reached a certain value the wires ignited, opening the circuit. Aluminum wires of $0.8 \mathrm{~mm}$ diameter were used.

Figure 5 shows a current pulse from a discharge with a solid connector (without the exploding wire switch), along with five recorded interrupted pulses achieved with the exploding wire switch. The interrupted current pulses have a lower peak and amplitude than the uninterrupted one.

This leads to less energy being transferred to the sample, when compared to the uninterrupted pulse.

\subsubsection{Measurements of the sample velocity}

The sample velocity was measured using an Ohio Manufacturing Institute Photon Doppler Velocimetry (PDV), which measures velocity based on the Doppler effect. A laser beam of $1550 \mathrm{~nm}$ in wave length is split into two; half is used to illuminate a test specimen and half as a reference. The beam that is used to illuminate the specimen is reflected and captured by a sensor. If the specimen is in motion the frequency of the reflected wave will be different than the original beam and the difference in the frequencies, the beat frequency, is then used to obtain the velocity of the specimen [22,23]. The PDV outputs a voltage versus time signal with a frequency equal to the beat frequency. The frequency spectrum of the signal was calculated using Matlab(c)and then the velocity was calculated using the formula [22,23];

$$
V=\text { beat frequency } * \text { wavelength } / 2 \text {. }
$$

A representative velocity data set calculated from PDV readings is shown in Fig. 6. The ring velocity profile is clearly discernible and relatively smooth. Several gaps in the velocity profile are usually present due to gaps in the calculated spectrum of the signal. To determine the accelerations, a curve was fit to the data and the velocity obtained from the fitted curve was used to calculate the accelerations. Figure 6 also shows a fitted curve. Very good fits were obtained from the data. 


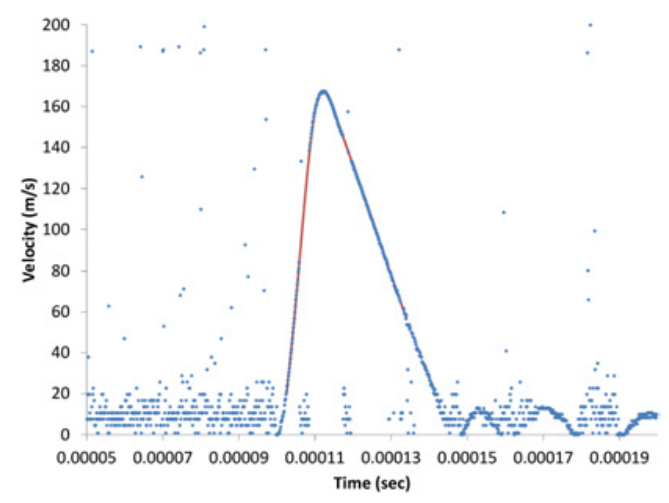

Figure 6. Velocity extracted from the experimental PDV readings (symbols) together with the data fit (solid line) used to calculate the accelerations.

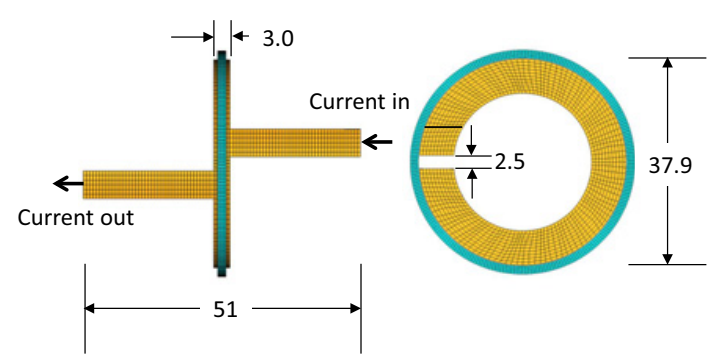

Figure 7. Single turn coil with ring in testing position. The figure is from the FEM mesh used for modelling the experiments. All dimensions in $\mathrm{mm}$.

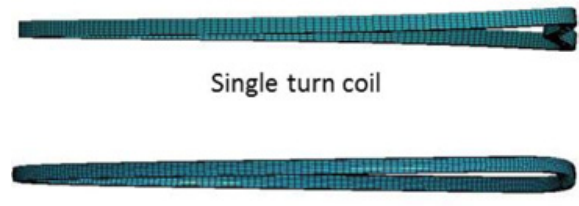

3-turn spiral coil

Figure 8. Predicted shapes of a sample ring formed with the single turn coil used in this work and a 3-turn spiral coil.

\subsubsection{Coil}

The coil is a critical part of the apparatus. The coil geometry and material will affect the amount of energy transmitted to the sample and play a significant role in determining the magnitude and direction of the forces induced on the sample ring. A single turn copper coil was designed and built for this work (Fig. 7). The goal of the design was to reduce the coil impedance, maximize strength and minimize non-radial (out-of-plane) movement of the sample. By reducing the windings to one, the inductance of the coil is reduced, allowing for higher peak currents and thus higher induced forces. In multiple winding coils the windings induce forces on each other, resulting in significant stress on the windings. With only one turn the winding only affects itself, reducing the forces on the coil and resulting in increased coil life. The non-radial movement of the ring was not eliminated, but simulations showed that it is reduced when compared to a 3-turn spiral coil, as can be seen in Fig. 8.

The $2.5 \mathrm{~mm}$ gap present in the single turn coil resulted in a reduction of the induced forces on the ring in the area

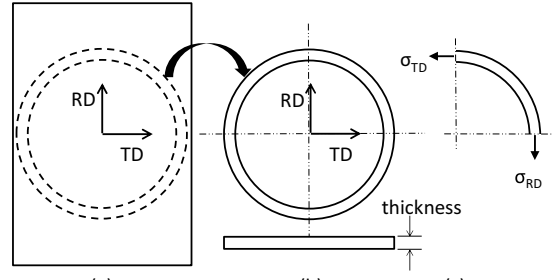

(a)

(c)
Figure 9. Rings are obtained from sheet metal (a) to (b). $\mathrm{TD}=$ transverse direction $\mathrm{RD}=$ rolling direction.

adjacent to it. The effect of this gap on the samples will be addressed in Section 4. The gap width was required due to machining limitations.

\subsection{Material and sample geometry}

The material tested in this work was $1 \mathrm{~mm}$ sheet of AA $5182-\mathrm{O}$, which has nominal yield strength of $130 \mathrm{MPa}$. Detailed constitutive characterization of this material at strain rates up to $1,000 \mathrm{~s}^{-1}$ has been performed by [24].

\subsubsection{Sample geometry}

Samples should have a cross section small enough to ensure that only hoop stresses are present [5] and should have a small aspect ratio to achieve plane stress [17]. For a sheet metal sample, these conditions are best satisfied by a square cross section, with the length of the sides equal to the thickness of the sheet. To minimize the effect of materials processing, the rings were cut from the stock sheet material (Fig. 9). This resulted in geometrically uniform and flat specimens.

It is well established that sheet materials have different strengths along the rolling direction (RD) and the transverse direction (TD) to rolling. Rings made as described above will have different strengths along the circumference, as the strength goes from the RD to the TD values (Fig. 9-c). Work on measuring the anisotropy is ongoing and the results present herein do not include studies of anisotropy.

\section{Numerical modelling}

A numerical model was developed to gain insight into the general behaviour of a ring during the tests. An EM capable version of the commercial software LS-Dyna [25] was used. The material model used was a tested isotropic piece-wise-linear plasticity material model for a similar alloy (AA 5754) that was calibrated and tested for EM forming models [20]. No rate effects were introduced at this stage of model development. A resistivity of $55 \mathrm{n} \Omega . \mathrm{m}$ was assumed for the samples. The mesh used for the model is shown in Fig. 7. Both the coil and ring were modelled with brick elements. The ring was modelled with 5 elements through both thickness and width, which resulted in 6,250 elements. The coil was modelled with 10 elements through thickness and width, for a total of 16,000 elements. An experimentally measured current profile was used as the current input. The model was not intended to exactly reproduce the test conditions, but to 


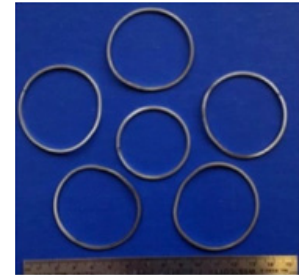

(a)

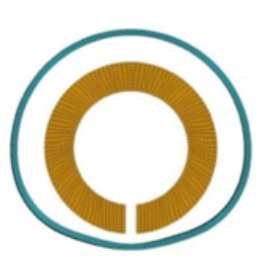

(b)
Figure 10. Tested samples surrounding an un-deformed ring (a) and final predicted shape of an expanded ring (b).

Table 1. Experimental peak currents and velocities, with final strains for the samples tested.

\begin{tabular}{|c|c|c|c|}
\hline Sample & $\begin{array}{c}\text { Peak } \\
\text { Current } \\
(\mathbf{k A})\end{array}$ & $\begin{array}{c}\text { Peak } \\
\text { Velocity } \\
(\mathbf{m} / \mathbf{s})\end{array}$ & $\begin{array}{c}\text { Final } \\
\text { strain }\end{array}$ \\
\hline 1 & 102 & 164 & 0.29 \\
\hline 2 & 97 & 148 & 0.21 \\
\hline 3 & 107 & 166 & 0.25 \\
\hline 4 & 107 & 167 & 0.25 \\
\hline 5 & 110 & 171 & 0.25 \\
\hline
\end{tabular}

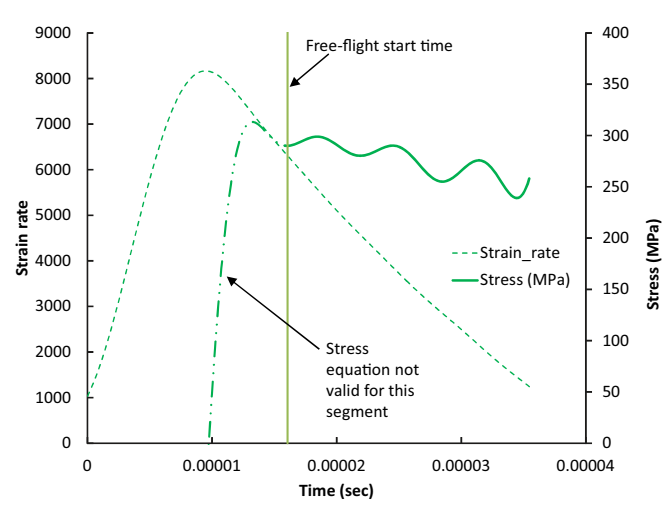

Figure 11. Strain rate and stress versus time for a single sample.

model the general behaviour of the test, thus the simplified material model used was deemed acceptable. A detailed description of the solution technique can be found in [20].

\section{Results and discussion}

The rings from five experiments are shown in Fig. 10-a. The final shape is not a perfect circle, with a flattened area visible on all samples. The numerical simulations indicate that the final shape is the result of the $2.5 \mathrm{~mm}$ gap discussed above (Fig. 10-b). An additional source of the final shape could be minor variations in the positioning of the sample on the coil.

The basic test parameters and final true strains of the sample are shown on Table 1. It can be seen the current pulse for sample 2 was lower than all the other ones, which resulted in the lowest measured peak velocity. This is reflected in the stress data shown below.

Experimental strain rate and stress data for sample 1 are shown plotted versus time in Fig. 11. The point where the current pulse stops and free-flight is reached is indicated with a line and shows that a significant period of free-flight was achieved. Strain rates peak at roughly

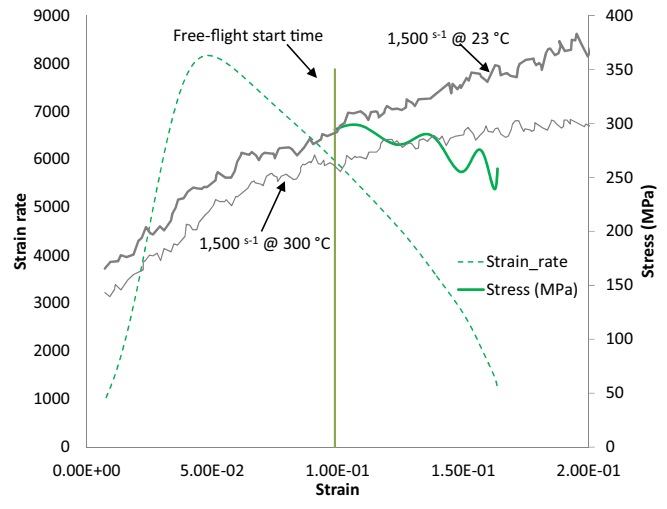

Figure 12. Strain rate and stress versus time for sample 1. Data for $1,500 \mathrm{~s}^{-1}$ from [26].

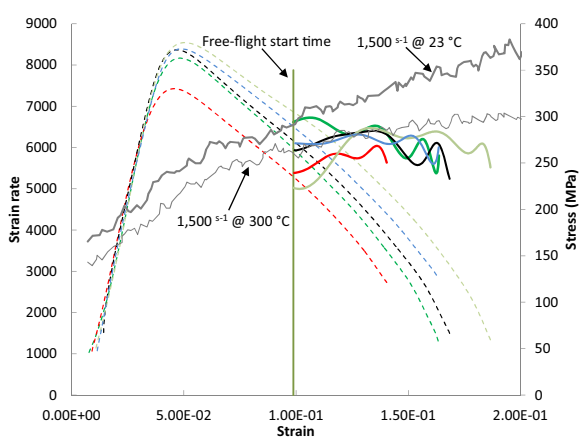

Figure 13. Strain rate and stress versus time for the five samples tested. Data for $1,500 \mathrm{~s}^{-1}$ from [26].

$8,000 \mathrm{~s}^{-1}$ and decrease to approximately $5,500 \mathrm{~s}^{-1}$ at the start of free-flight, ending at $1,000 \mathrm{~s}^{-1}$. The strain rates decay as the test progresses. This poses some challenges to data fitting that are being resolved as part of ongoing work. The part of the stress-strain curve shown in a dashed line represents the period were Eq. (4) is not valid due to the presence of induced forces. Subsequent graphs will not present this portion of the curve.

Figure 12 shows the strain rate and stress plotted versus the true strain calculated using Eq. (5). The figure also includes published data from Hopkinson bar tests carried out on AA 5182 at $1,500 \mathrm{~s}^{-1}$ at 23 and $300{ }^{\circ} \mathrm{C}$ [26].

Data for all five tests is shown in Fig. 13. There is relatively good repeatability, especially given the nature of this experiment. The tests are reasonably repeatable; with only one test (sample 2) deviating significantly from the rest. Of the published data presented in the figure, the data for the elevated temperature test is the closest to the current work. Although no firm conclusions can be drawn at this time, the data indicates that thermal softening could be affecting the dynamic strength of the material in the ring expansion experiment.

\subsection{Joule heating}

Significant temperature increases can be produced in the sample by the induced currents through Joule heating [10]. The temperature change on a ring sample is given by [10]:

$$
\dot{T} j=\frac{R I^{2}}{C_{p} \Lambda \rho} .
$$


Where $\dot{T}_{j}=$ temperature change, $R=$ resistivity, $I=$ sample current, $C_{p}=$ heat capacity, $\Lambda=$ sample volume, $\rho=$ density.

Ideally, the current induced in the ring would be measured directly. Unfortunately, that capability was not available to the authors at the time of writing. In lieu of an actual measurement, a numerical model was used to obtain an approximate value of the temperature rise. Using the current in the sample predicted by the model and Eq. (8), it was determined that the sample temperature rise is on the order of $200{ }^{\circ} \mathrm{C}$, which is in the range where thermal softening effects can be significant [27].

\section{Conclusions}

The interrupted pulse EM expanding ring test has significant potential for material characterization at high rates of strain. The combination of significant free-flight and velocity measurements using the PDV provide stress values from an analysis that is free of the additional assumptions that are common in expanding ring tests. The strain rates achieved were below the desired value of $10,000 \mathrm{~s}^{-1}$, but the indications are that strain rates of $10,000 \mathrm{~s}^{-1}$ are possible. Future challenges will include fitting the data to a material model, due to the decaying strain rates experienced by the samples, and determining the sample temperature rise to account for the thermal softening effects produced by the Joule heating. The current coil design met the desired criteria and is a viable approach for ring expansion tests.

The authors greatly appreciate the financial support APC, NSERC, Canada Research Chairs Secretariat, ORF, Ford Research \& Advanced Eng., Amino Corp., and ArcelorMittal.

\section{References}

[1] V. Psyk, D. Risch, B. Kinsey, A.E. Tekkaya and M. Kleiner, J. Mat. Proc. Tech., 211 (2011)

[2] V.S. Balanethiram, G.S. Daehn, 1994. Scripta Metal. Mater. 30 (1994)

[3] J.M. Imbert, M.J. Worswick, S.L. Winkler, S. Golovashchenko,V. Dmitriev, SAE Trans. J. Mater. Manuf. SAE paper number 2005-01-0082 (2005)
[4] J. Imbert, M. Worswick, J. Mat. Proc. Tech., 212-9 (2012)

[5] C. Hoggatt, R. Recht, Exp. Mechs., October (1969)

[6] R.H. Warnes, R.R. Karpp, P.S. Follansbee, J. Phys., C5, 46-8 (1985)

[7] R.H. Warnes, R.R. Karpp, P.S. Follansbee, J. Eng. Mat. Tech, 108 (1986)

[8] P.C. Johnson, B.A. Stein, R.S. Davis, U.S. Army Mat. Res. A. Rep. No. WAL TR 111.2/20-6 (1962)

[9] W.H. Gourdin, S.L. Weinland, R.M. Boiling, Rev. Sci. Instrum., 60-3 (1989)

[10] W.H.Gourdin, J. App. Phys., 65 (1989)

[11] D. Landen, S. Satapathy,D. Surls, 5th IEEE Int. Pulsed Power Conf. (2005)

[12] D. Landen, S. Satapathy, D. Surls, IEEE Trans. Mag., 43-1 (2007)

[13] D. Landen, D. Wetz, S. Satapathy, S. Levinson, IEEE Trans. Mag., 45-1 (2009)

[14] G. Daehn, Y. Zhang, S. Golowin, K. Banik, A. Vivek, J. Johnson, G. Taber, G. Fenton, I. Henchi, P. L'Eplattenier, $3^{\text {rd }}$ Int. Conf. on High Speed Forming (2008)

[15] G. Taber, G, Daehn, A. Vivek, dissertation submitted to the Ohio State University (2008)

[16] J. Johnson, G. Taber, A. Vivek, Y. Zhang, S. Golowin, K. Banik, G. Fenton, G. Daehn, Steel Res. Int., 80-5 (2009)

[17] J. Johnson, G. Taber, G. Daehn, $4^{\text {th }}$ Int. Conf. on High Speed Forming (2010)

[18] A. Rajendran, I. Fyfe, J. App. Mech., 49 (1982)

[19] I. Henchi, P. L'eplattenier, G. Daehn, Y. Zhang, A. Vivek, N. Stander, $10^{\text {th }}$ Int. LS-DYNA Conf. (2008)

[20] J. Imbert, University of Waterloo Ph.D. thesis (2010)

[21] R. Bealing, P.G. Carpenter, J. Phys. E., 5 (1972)

[22] O. Strand, L. Berzins, D. Goosman, W. Kuhlow, P. Sargis, T. Whitworth, Vel. Using Heterodyne Techs. Conf., paper UCRL-CONF-206034 (2004)

[23] O. Strand, D. Goosman, C. Martinez, T. Whitworth, W. W. Kuhlow, Rev. Sci. Instrs., 77 (2006)

[24] T. Rahmaan, A. Bardelcik, J. Imbert, C. Butcher, M.J. Worswick, Submitted I. J. Impact. Eng. (2014)

[25] P. L'Eplattenier, G. Cook, C. Ashcraft, M. Burger, J. Imbert, M. Worswick, Steel Res. Int., 80-5 (2009)

[26] R. Smerd, S. Winkler, C. Salisbury, M. Worswick, D. Lloyd, M. Finn, I. J. Impact Eng., 32 (2005) 